\title{
Building an Extensive Experience in Video Games and Movies, a Transmedia Storytelling
}

\author{
Octavianus Frans \\ Visual Communication Design \\ School of Design, \\ Bina Nusantara University \\ Jakarta, Indonesia \\ ockland@binus.edu
}

\author{
Jonata Witabora \\ Visual Communication Design \\ School of Design, \\ Bina Nusantara University \\ Jakarta, Indonesia \\ jowitabora@binus.edu
}

\begin{abstract}
Transforming video games into movies and transforming movies into video games has been a common thing nowadays. With advanced technology, what can be done in a video game can also be done in a movie, and vice versa. Good attention to details is important in a transformation process as the final product has to be as good as the original one, if not better. To be able to do well in transforming an art form to another, it is important to understand the whole process and how it was first done.
\end{abstract}

Keywords - alih wahana; media transformation; video games; movies

\section{INTRODUCTION}

In his book, Alih Wahana, Sapardi Djoko Damono explains the basic principles of art forms transformation. The word alih wahana (media transformation) is a term used by Damono referring to a transformation of an art form into another. Translation and adaptation are the examples of media transformation. Art is considered a media that can always change when used to express one's ideas and feelings. [1]

Transforming one art form into another is a common thing in the world of art. By transforming one art form into even more than another art form, the idea of the art will be ever-present. Media transformation doesn't only mean turning one art form into another but it also has to transform it so it will fit the other art form right. The most common example of media transformation is adapting novels into movies, widely known as ecranisation. Another common example is adapting video games into movies, and vice versa.

The latest technology allows video games to be one of the pop cultures that are growing quickly. Humans were born liking to play games [1], and technology makes a way for video games to be more likeable and easier to access. People can now find various ways to access video games; they come in mobile phones, computers, and even as console games.

The video games industry has turned into one of the big industries. It doesn't only profit from the video games sales but also from selling merchandises, action figures, and comic books. Comic books industry does the same thing. In both industries, the main attraction is the characters.
A transformation of video games into movies is a common thing nowadays. Movies have sort of turned into a media to expand video games ideas; and transforming a video game into a movie has been a mandatory thing to do once the video game has reached a certain level of success. This doesn't only happen in the video games industry but also in the literature industry as many best-sellers novels have been transformed into movies. This might make it look like transforming either literature works or video games into movies is the mark of success, as a movie is the complete media to not only express ideas and feelings but also to attract more people to enjoy it, leading to bigger profit for both the industry and the artists involved. As a form of media, video games have all the right materials that can be transformed into movies.

\section{RESEARCH METHOD}

This journal will use literature study approach which means the writers will gather all sources related to film studies, video games and studies concerning printed media to electronic media transformation. The writers will then look into the sources and select which ones can support the journal best. The writers will also make observations of video games and movies

\section{ELEMENTS OF TRANSFORMATION}

Transforming video games into movies is something that has been done many times now but the success of a video game doesn't necessarily mean that its movie will be as successful, and vice versa. A careless transformation process is one reason why the video game and its movie version are unable to have the same level of success.

Both video games and movies are audio visual medias which have the same forming elements such as storyline, characters and sounds. The elements can either break or make both medias' success, all depending on the transformation process. Doing a transformation in two media that have similar elements might be easier as there should not be too many elements to change but it also can limit ideas and rooms to improvise that will end up with elements adjustments, causing differences in the transformed media. One needs to be 
meticulous in understanding, adding, subtracting and changing elements in both medias so they will have the same good quality.

We would need to understand how both medias are formed, based on their elements, characters and the expected goals.

In formal studies, the principles found in movies can also be found in video games. By looking into these principles, it is possible to compare how a principle is used in both medias.

\section{A. Characters}

In the early years of the video games industry, games like Pac-Man (1980) and Tetris (1984) have simple rules for people to follow. The simple rules were hugely affected by limited access to good graphic. A storyline did not play a big role in video games in this era, characters and actions did. Characters from video games in this era, like Donkey Kong (1981), became very well-known. The growing graphic technology made it possible for Super Mario Bros. (1985), to be one of the videos games with lively characters and more challenging actions and complex storylines. Mario and Luigi in Super Mario Bros. were and still are a big icon in the video game world. It is also one of the video games that had successfully been transformed into more than one medias which were animation movies and serial television.

Characters indeed play a big role in video games, just like in movies, where they have to be specifically created with their own dramas and conflicts that will add to the complexity of a storyline. Creating strong characters is important to attract possible enthusiasts, both in video games and in movies.

Main characters, however, need to be adapted with its media. Visually, characters in the movie Street Fighter (1994) couldn't be transformed exactly like how they looked like in the game. The real characters were just $2 \mathrm{D}$ drawings and they needed to be recreated as if they were real humans in the real world. The characters would look out of place if they were not recreated.

The same thing happened in X-Men the movies. The characters in the movies appeared to wear black when they actually wore colorful costumes in the comic books. This thing was adjusted to match the movies' goals; to present the characters as sophisticated and to give the audience a hightech ambience.

\section{B. Narrative}

There are six types of game activities in the video game world which are [3]:

- Agon Games focusing on competition.

- Alea Games counting on chances, gambling games for example.

- Mimicry

Role-play games.
- Ilinx

Games that creates a temporary disruption of perception.

- Exploration

Games focusing in adventures.

- Social play

Games requiring players' interaction and cooperation

Players' actions in a video game will help to form its narrative. Every action will unlock a new level; reveal a new storyline that will eventually lead players to the end of the game. This process creates a joy in playing the game. In total, a game's duration can reach up to dozens, even hundreds of hour and players have an active role in deciding their desired ways of finishing the game. Players usually decide what to do with their avatars first, then with the storyline. Most of the times, games developers will insert some cut scenes to let players experience how their actions can affect the storyline.

The game Heavy Rain (2010) has a gameplay with interactive cut scenes where the game visual look looks like movie scenes but the players can decide what to do with their avatar in certain times. Cut scenes make a game flow just like a movie which has a linear plot. Players playing Heavy Rain will feel like they are watching a movie, with a storyline they can control.

Video games developer transforming movies into video games have to be able to explore and expand the game narrative in order for the video games to be more interesting. This might result in new plots and characters, and even new storylines. The main problem with transforming video games into movies is the storyline. The movie team has to reduce dozens and hundreds of hours to just one to two hours without reducing the quality of the movies. It has to transform the pleasure of playing a video game to the pleasure of watching the movie.

Tomb Raider series (1996-2013) had been transformed into two successful movies. In the movies, the storyline was added with dramas and love stories, and also with others new characters so the movies could still be interesting and enjoyable to both players and non-players. The movies were of course different from the video games series that only focused on the action and tension, made of puzzles and game levels.

\section{Mise-en-Scéne}

Mise-en-Scéne is a principle in the world of movie which analyzes how a certain surrounding is displayed in a movie frame and which things need to be in the frame.

By analyzing it, one would be able to know which things do not show in the frame but are actually important to be in it to help display the right surrounding. For example, a visual of blood drops and splatters are important to perfect a spooky feeling to a video game or movie. In video games, blood splatters can even be an indication to make an action. In Silent 
Hill (1999), blood splatters indicated a monster in a room. In Metal Gear Solid (1998), boxes indicated safe places to hide.

The existence of blood splatters and boxes as a visual in a scene can have mean something more than just to create the right atmosphere in a game [2].

\section{Technology and Scenes}

Action in video games has been getting more complex every time. Superhero moves in comic books are not very difficult to create, using interesting visual effects. At first the moves were difficult to transform into scenes in a movie. Lara Croft's ability to do a back flip in the air and shooting with two hands was easily created in Tomb Raider games. However, it was impossible to do the same thing in the movies and adjustments had to be made, like adjustment on moves that were still doable in real life but looked not too different from the games. As visual technology progressed, imitating moves from video games in movies becomes more possible.

The Matrix (1999) introduced Bullet Time technology, a visual effect that slows down the passage of time so that an observer can see individual bullets flying throughout the scene at a conceivable rate, or any fast-moving object, sometimes with streaks and trails made visible. This visual effect then became more popular, thanks to Max Payne video game (2005) and other action video games like Prince of Persia (first released in 1989) and Infinity Blade (2010). Technologies like green screen and 3D modeling have made it possible for video games to create visual effects and illusions that are as good as the ones in movies.

It would be effortless to transform movies like The Lord of the Ring trilogy, which maximized the use of 3D technology in creating the characters and the scenes, into video games as the transformation could also use the same 3D modeling techniques. The whole thing seen in the movie could be seen and experienced again in the video game. Another technology, face scan, even lets games developers transform the actors in a movie into avatars with the same features in a video game.

In the movie The Matrix: Revolutions (2003), 3D technology was used to create stuntmen, to replace the real actors playing Neo and Smith in a fighting scene, as some scenes and actions that were impossible to be done by a person.

Scenes with visual effects are created to let people have a taste of experiencing spectacle and sensation and to wow them when playing the game or watching the movie. Both media use the same technologies and principles to make both video games and movies interesting visually.

Video games and movies are both visual medias. Media transformation from video games into movies and of movies into video games has clear visual rules, unlike transforming literature works into movies, for example. Media transformation from video games into movies and of movies into video games has already had collective visual expectations and not just individual visual imaginations.

Technology has an important part of bringing the world of movies and video games closer. Visually, all scenes present in a video game can always be recreated in its movie version and all scenes in a movie can also be recreated in the video game version. The transformed scenes in a media can have a lot of similarities with scenes in the original media but it can also have differences. It all depends on the approach. There are no longer limitations of ideas and room for improvisation that can possibly cause the visual similarities and the difference. The visual transformation from video games into movies and vice versa, if done right, can result in visual that is as good as the one in the original media. However, if the transformation is done poorly, it might cause a bad result instead.

\section{CONCLUSION}

Movies and video games are two completely different medias, despite their elements similarities. Video games are an active and co-creative media where storyline flows from the plot made by games developers and from the players' interactions in the video games themselves. Avatars in video games are more or less the representation of players. A video game lets players have an illusion and control over the game and the plot, as if they are actually the avatar, going on an adventure in the game. An alternative ending in video games is a common gameplay as it always alternate, depending on which actions and storyline the avatar chooses along the game.

Movies, on the other hand, are a passive media as people watching them can only follow the storyline. People usually are sort of forced to see what will happen in the next scene. They can only watch and enjoy movies the way they are made. They have no control in changing the storyline or decide what a character should and should not do.

The difference in characteristics is a fundamental thing that needs to be observed better. There are a lot of movies that failed in transforming video games and there are also a lot of video games that did not do well in transforming movies. This happens when either a games developer or a director fails in following the right structure in transforming a media into another, and fails in understanding one or both of the medias.

Nintendo game designer, Shigeru Miyamoto once explained his views in video games and movies. Miyamoto says, "I think that video games, as a whole, have a very simple flow in terms of what's going on in the game. We make that flow entertaining by implementing many different elements to the video game to keep the player entertained. Movies have much more complex stories, or flow, to them, but the elements that affect that flow are limited in number. So I think that because these surrounding elements in these two different mediums vary so greatly, when you fail to take that into account then you run into problems," [4] 


\section{REFERENCES}

[1] Damono, Sapardi Djoko (2012) Alih Wahana, EditumUSA: Abbrev. of Publisher, year, ch. $x$, sec. $x$, pp. $x x x-x x x$.

[2] Rutter J., Bryce J. (Eds) 2006 Understanding Digital Games, Sage.

[3] Eskelinen, M. (2001) The Gaming Situation, in Game Studies: The International Journal of Computer Game Research, 1(1), accessed on May 25, 2014 on http:/gamestudies.org/0101/eskelinen/.

[4] Rogers, Emily. Shigeru Miyamoto's Aprreciation For Film. Dromble, accessed on May 25, 2014 on www.dromble.com. 